\title{
Effect of medium composition on the apparent sensitivity of Pseudomonas aeruginosa to gentamicin
}

\author{
L. P. GARROD AND PAMELA M. WATERWORTH
}

From the Royal Postgraduate Medical School, London

SYNOPSIS The diameter of inhibition zones in cultures of $P$ s. aeruginosa produced by discs of gentamicin varied on different media, as did the minimum inhibitory concentration (MIC) when the antibiotic was included in the medium.

These variations, which were small in parallel tests of Esch. coli, were found to depend on the general composition of the medium, but were also affected by the agar used to solidify it.

An agar on which the MIC was low had a low magnesium content, and two on which it was high had a high content. The addition of magnesium sulphate in increasing amounts to a medium of low content progressively increased the MIC.

It thus appears that a high magnesium content, which is necessary for pyocyanin production, also increases the resistance of this organism to gentamicin.

The difficulty of determining the sensitivity of Ps. aeruginosa to gentamicin as a guide to treatment is emphasized. The best method appears to be direct comparison with another strain of the same organism of known sensitivity.

It is well recognized that the activity of streptomycin and other aminoglycosides in vitro is affected by medium composition, important factors being $p \mathbf{H}$, peptone, and electrolyte content. That gentamicin is also affected is evident in discrepancies among previous findings on the activity of this antibiotic against Ps. aeruginosa. In an early description of gentamicin (Weinstein, Luedemann, Oden, and Wagman, 1963) the minimum inhibitory concentration (MIC) for five out of eight strains is stated as $\mathbf{0 . 1}$ to $0.3 \mu \mathrm{g} / \mathrm{ml}$, the remainder having an MIC of $0.6,1 \cdot 2$, and $1 \cdot 2 \mu \mathrm{g} / \mathrm{ml}$. Barber and Waterworth (1966) found 25 strains to be inhibited by 1 to 8 (most often 2) $\mu \mathrm{g} / \mathrm{ml}$, and in a later publication from the same department Darrell and Waterworth (1967), who mention that a different medium was used for these tests, found 44 strains to be inhibited by 0.25 to 16 (most often 4) $\mu \mathrm{g} / \mathrm{ml}$. (These figures exclude three strains which became resistant during treatment). The effects reported here, which are exceptionally large, are unusual in that they affect only this one species and therefore alter its apparent sensitivity relative to that of others. These changes may be brought about not only by the general composition

Received for publication 28 May 1969. of the medium itself but also by the agar used for solidifying it.

\section{MATERIALS AND METHODS}

CULTURE MEDIA The proprietary media used were: Diagnostic sensitivity test agar (Oxoid); Nutrient broth no. 2 (Oxoid); Mueller-Hinton broth (Baltimore Biological Laboratories); Infusion broth (Southern Group Laboratory); Digest broth (Southern Group Laboratory); Columbia agar (Oxoid).

Of these diagnostic sensitivity test agar and Columbia agar were also kindly supplied to us by Oxoid Ltd without agar, in order that different agars could be added to them.

The agars used were agar no. 1 , Ionagar no. 2 , and agar no. 3 (all Oxoid), in concentrations of $1 \cdot 0,1 \cdot 0$, and $1.2 \%$ respectively. In one experiment fibre agar (Southern Group Laboratory) was also used.

Some determinations of MIC were also done in 'blood' and 'urine'. To prepare these whole citrated blood was lysed by freezing and thawing and diluted with an equal volume of normal saline, and pooled normal urine was adjusted to $p \mathrm{H} 6.8$ and sterilized by filtration. The blood medium was subcultivated to determine whether there had been growth in it.

STRAINS OF BACTERIA Most of these were recent isolates, but those of Ps. aeruginosa included NCTC 10490 and 
those of Esch. coli NCTC 10418. In tests using multiple strains, significant differences in their behaviour were never observed.

DISCS These were $10 \mu \mathrm{g}$ gentamicin discs supplied by Mast Laboratories. They were shown by exhaustive tests to behave consistently.

MIC DETERMINATIONS Plates containing falling concentrations of antibiotic were prepared by adding $14.5 \mathrm{ml}$ melted and cooled medium to $0.5 \mathrm{ml}$ solution and thorough mixing. These were inoculated with a multiple replicator from an approximately 1 in 500 dilution of an overnight broth culture. One drop $( \pm 0.02 \mathrm{ml})$ of this dilution was added to $2 \mathrm{ml}$ volumes of medium when determinations were done in broth.

\section{RESULTS}

The original observation leading to this work was that the size of inhibition zones surrounding gentamicin discs on cultures of Ps. aeruginosa varied considerably with the medium used, their diameter ranging from 16 to $27 \mathrm{~mm}$. The differences were consistent when six different strains were tested. In parallel tests with other species, including $E$. coli, Pr. mirabilis, Pr. rettgeri, and Staph. aureus, only small differences in zone diameter (up to $4 \mathrm{~mm}$ ) were observed. Corresponding differences were found in plate dilution tests, the MIC of gentamicin for $\boldsymbol{P}$ s. aeruginosa varying up to 16 -fold, whereas that for other bacteria varied considerably less.

These differences are shown in the left-hand columns of Table I, where it can be seen that the MIC of gentamicin for Ps. aeruginosa in six different broths varied from $0 \cdot 25$ to $8 \mu \mathrm{g} / \mathrm{ml}$, whereas that for Esch. coli varied only from $0 \cdot 25$ to $1 \mu \mathrm{g} / \mathrm{ml}$.

EFFECT OF THE AGAR USED Having reason to believe that not only the general composition of the medium, but that of the agar used to solidify it, might be a factor, we then solidified one medium, nutrient broth no. 2, with three different agars, agar no. 1, Ionagar no. 2 , and agar no. 3. The inhibition zones of $P$ s. aeruginosa produced by gentamicin discs on these media had diameters of 27,18 , and $17 \mathrm{~mm}$ respectively. Again there were only small differences in tests with other bacteria.

In order to explore this effect further, the MICs of gentamicin for Ps. aeruginosa and Esch. coli were determined in six different media, both as liquids and solidified with different agars. The results (Table I) show that none of the agars has a significant effect on the MIC for Esch. coli, but there are very pronounced effects on those for Ps. aeruginosa. When the MIC in broth was low, solidification with agar no. 3 increased it up to 32 -fold. When the MIC in broth was high, the addition of these agars made little difference. All the media were unaffected by the addition of agar no. 1. Fibre agar gave similar results to agar no. 3. Agar no. 2 also behaved similarly: neither was tested in all the media.

The effects of agars nos. 1 and 3 on the activity of gentamicin against Ps. aeruginosa are illustrated in Figure 1. Whereas agar no. 3 greatly reduces the width of the inhibition zone of this organism, that of Esch. coli is almost unaffected. Thus in a test using this as a standard organism, the strains of $P$ s. aeruginosa would be adjudged more sensitive than the control on one medium and considerably less so on the other.

THE EFFECT OF MAGNESIUM CONTENT The addition of agars nos. 2 and 3 to a medium in which the MIC of gentamicin for Ps. aeruginosa is low also had the effect of increasing pigment formation. Pyocyanin formation requires the presence of magnesium (Robinson, 1932) and is enhanced by increasing concentrations up to $0.07 \%$ of $\mathrm{Mg}_{2} \mathrm{SO}_{4} .7 \mathrm{H}_{2} \mathrm{O}$, maximum production continuing up to much higher concentrations (Burton, Campbell, and Eagles, 1948). It therefore seemed possible that $\mathrm{Mg}$ content might be a factor in determining sensitivity to gentamicin.

This hypothesis is strongly supported by the following facts with regard to the $\mathrm{Mg}$ content of

\section{TABLE I}

MIC $(\mu g / m l)$ OF GENTAMICIN FOR Ps. aeruginosa AND Esch. coli IN DIFFERENT MEDIA AS BROTH AND SOLIDIFIED WITH DIFFERENT AGARS

\begin{tabular}{|c|c|c|c|c|c|c|c|c|c|c|}
\hline \multirow[b]{2}{*}{ Medium } & \multicolumn{5}{|c|}{ Ps. aeruginosa } & \multicolumn{5}{|c|}{ Esch. coli } \\
\hline & Broth & $\begin{array}{l}+ \\
\text { Agar } \\
\text { No. } 1\end{array}$ & $\begin{array}{l}+ \\
\text { Agar } \\
\text { No. } 2\end{array}$ & $\begin{array}{l}+ \\
\text { Agar } \\
\text { No. } 3\end{array}$ & $\begin{array}{l}+ \\
\text { Fibre } \\
\text { Agar }\end{array}$ & Broth & $\begin{array}{l}+ \\
\text { Agar } \\
\text { No. } 1\end{array}$ & $\begin{array}{l}+ \\
\text { Agar } \\
\text { No. } 2\end{array}$ & $\begin{array}{l}+ \\
\text { Agar } \\
\text { No. } 3\end{array}$ & $\begin{array}{l}+ \\
\text { Fibre } \\
\text { Agar }\end{array}$ \\
\hline Diagnostic sensitivity test & $0 \cdot 25$ & $0 \cdot 25$ & 1 & 2 & 2 & 1 & $0 \cdot 5$ & 0.5 & 0.5 & 0.5 \\
\hline Nutrient broth no. 2 & 0.25 & 0.25 & 2 & 4 & 2 & 0.5 & 0.5 & 0.5 & 0.5 & 0.5 \\
\hline Mueller-Hinton broth & $0 \cdot 25$ & $0 \cdot 25$ & 2 & 8 & & $0 \cdot 25$ & 0.25 & 0.5 & 0.5 & \\
\hline Infusion broth & 2 & 2 & & 8 & 4 & 1 & 1 & & 1 & 1 \\
\hline Digest broth & 4 & 4 & & 8 & 4 & 1 & 1 & & 1 & 1 \\
\hline Columbia & 8 & 8 & & 16 & & 1 & 0.5 & & 1 & \\
\hline
\end{tabular}




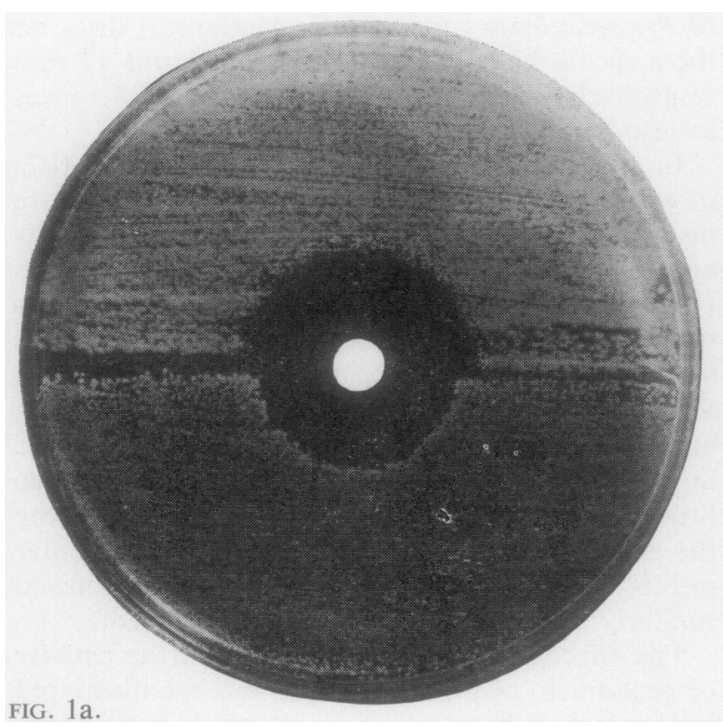

these agars and of some of the media used. The content of the three agars is: no. $10.03 \% \mathrm{w} / \mathrm{w}$; no. $20.32 \% \mathrm{w} / \mathrm{w}$; and no. $30.30 \% \mathrm{w} / \mathrm{w}$. Thus the addition of $1 \%$ of agar no. 1 will contribute only $3 \mathrm{mg} \mathrm{Mg}$ per litre to the medium, whereas the addition of $1.2 \%$ agar no. 3 will contribute $36 \mathrm{mg}$ per litre.

The Mg content of three of the broths used were determined by means of an atomic absorption spectrophotometer 290 (we are indebted for this investigation to Mr A. Brecker of Oxoid Ltd). They were as follows :diagnostic sensitivity test agar, $3 \cdot 2 \mathrm{mg}$ per litre; nutrient broth no. 2, $5 \mathrm{mg}$ per litre; and Columbia agar, $21 \mathrm{mg}$ per litre.

It thus appears that Columbia, the only one of these media in which the MIC is high, has a high $\mathrm{Mg}$

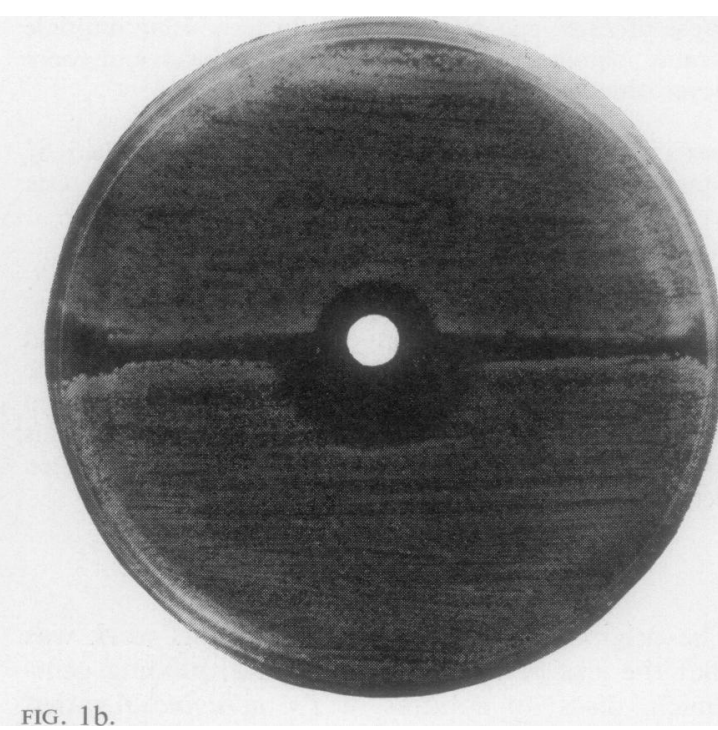

FIG. 1b. content, that of the others being much lower. Moreover agar no. 1, the addition of which does not alter the MIC, has a very low Mg content, whereas that of agars nos. 2 and 3, which increase the MIC greatly, is 10 -fold higher, and raises the content of the medium above that in Columbia broth.

There appears therefore to be a direct relationship between $\mathrm{Mg}$ content and resistance to gentamicin. This is further illustrated by the experiment set out in Table II. Progressive additions of $\mathrm{Mg}$ to diagnostic sensitivity test agar broth, which is deficient in $\mathbf{M g}$, 용 raised the MIC of gentamicin for Ps. aeruginosa 16-fold, but had no effect on its MIC for $E$. coli. The highest concentration added is roughly equiva- $\delta$ lent to that introduced by solidification with agar $₹$ no. 3 .

TABLE II

EFFECT OF THE ADDITION OF Mg ON THE MIC OF GENTAMICIN FOR Ps. aeruginosa AND Esch. coli IN DIAGNOSTIC SENSITIVITY TEST AGAR BROTH

Gentamicin $(\mu \mathrm{g} / \mathrm{ml})$

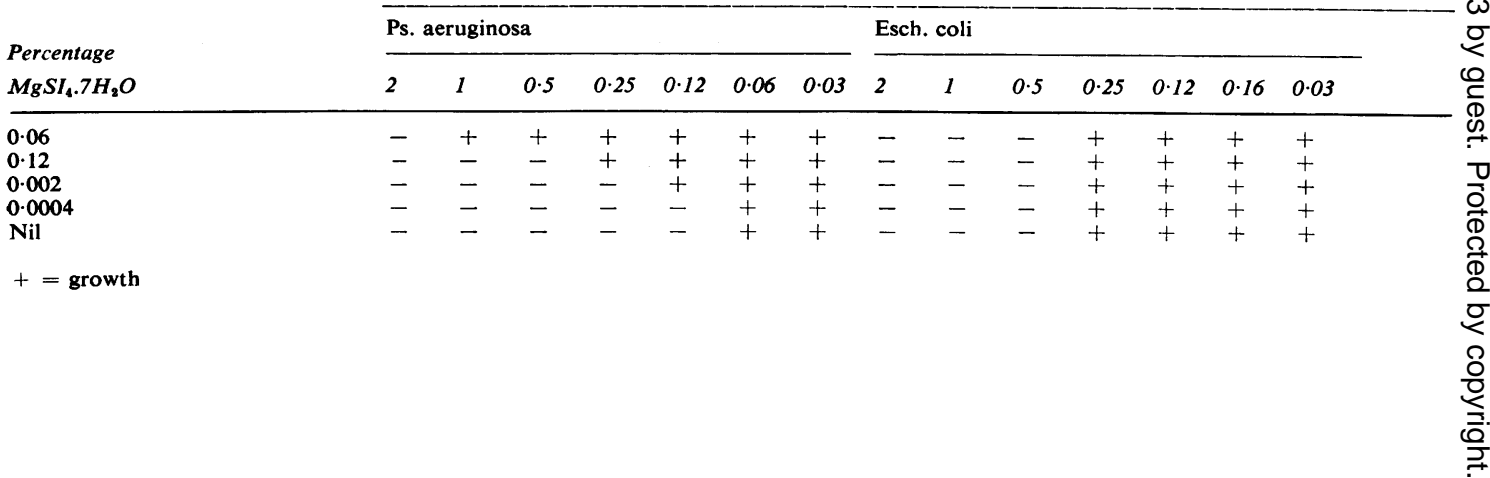




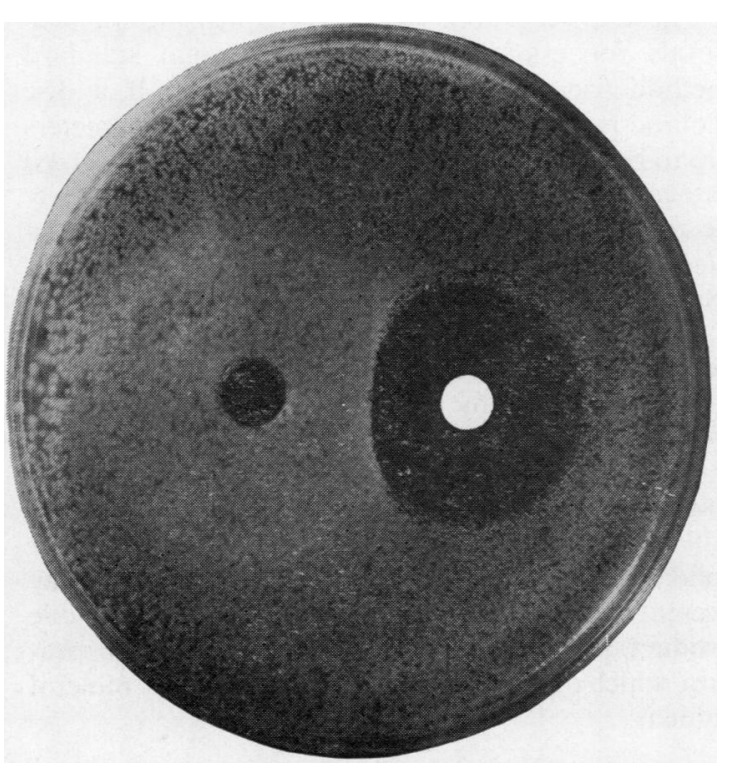

FIG. 2. Culture of Ps. aeruginosa on diagnostic sensitivity test medium solidified with no. 1 agar.

Disc contains gentamicin $10 \mu g$, cup contains $2 \%$ $\mathrm{MgSO}_{4} \cdot 7 \mathrm{H}_{2} \mathrm{O}$. This salt, diffusing into the surrounding medium, both enhances growth and reduces the width of the gentamicin inhibition zone.

The dual effect of increasing the $\mathrm{Mg}$ content of a medium deficient in $\mathbf{M g}$ is illustrated in Figure 2. The medium is diagnostic sensitivity test agar solidified with agar no. 1 , and there is a wide inhibition zone surrounding a gentamicin disc. To the left of this is a cup containing $\mathrm{Mg}_{2} \mathrm{SO}_{4}$ solution. Surrounding this is a zone of enhanced growth, and the adjoining inhibition zone is distorted by diffusion of the $\mathrm{Mg}$ salt into the area.

(It will be noted that diagnostic sensitivity test agar is a deficient medium for the growth of $\boldsymbol{P}$. aeruginosa when solidified with an agar of low $\mathrm{Mg}$ content, but this does not apply to the commercially available medium which is solidified with agar no. 2.)

TESTS IN BODY FLUIDS Since the result of a test of the sensitivity of Ps. aeruginosa to gentamicin is so much affected by the $\mathrm{Mg}$ content of the medium, what content may be accepted as giving a significant answer? One approach to this is to determine the MIC in actual body fluids, and the results of tests in blood and urine are given in Table III. Parallel tests were done with Esch. coli. The significant feature of the results is that the MIC for Ps. aeruginosa exceeds that for Esch. coli by four- and 16-fold, a difference corresponding to the results of tests in artificial media with an adequate $\mathrm{Mg}$ content,
TABLE III

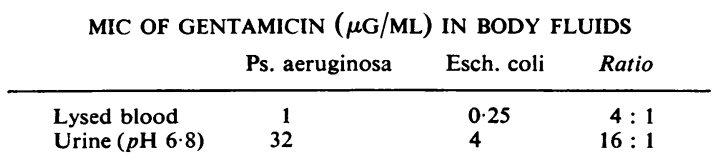

whereas in those with a low content this ratio is reversed. A medium with an adequate $\mathrm{Mg}$ content seems therefore to be indicated. The higher MIC for both organisms in urine must at least partly be due to its lower $p \mathrm{H}$.

EFFECT ON THE ACTION OF OTHER ANTIBIOTICS The MIC in plate dilution tests using media solidified with agars no. 1 and 3 for multiple strains of Ps. aeruginosa and various other enterobacteria were determined with some other antibiotics. A large difference was never seen with any organism other than Ps. aeruginosa, but in tests with streptomycin, kanamycin, and polymyxin, the MIC was usually lower on no. 1, the difference being most often two-fold, sometimes four-fold, but never greater.

\section{DISCUSSION}

Variations in the quality of agar have been reported as affecting the results of diffusion sensitivity tests because of an effect on the diffusibility of the antibiotic. According to Bechtle and Scherr (1958) much larger inhibition zones are produced by a polymyxin disc on medium solidified with $0.75 \%$ of Ionagar 2 (Oxoid) than on one containing $1.5 \%$ of conventional agar. A similar effect was obtained by Kunin and Edmondson (1968) with 'agarose' ('a neutral polysaccharide extracted from agar'), which enhanced the diffusion not only of polymyxin but of aminoglycosides.

An effect of agar on the activity of antibiotics, as distinct from their diffusibility, is reported by Hanus, Sands, and Bennett (1967) who determined MIC in broth and in the same medium solidified with $(a)$ unwashed and $(b)$ washed agar. These concentrations were lowest in the broth, somewhat higher in medium containing unwashed agar, with differences between the two solid media of < two-fold for streptomycin, about six-fold for neomycin and kanamycin, and nearly 25 -fold for polymyxin. These authors pointed out that divalent cations have been shown to reduce the activity of various antibiotics, that $\mathrm{Ca}, \mathrm{Mg}$, and other metallic cations are often bound to agar, and that the effect of washing may well be to remove these. They did not prove this, or identify the cation principally concerned. We are unable to relate these findings to our own, because the organism exclusively used was Staph. aureus, which 
in our experience is unaffected by factors controlling the MIC for Ps. aeruginosa.

Magnesium has long been known to be not only essential for the growth of Ps. aeruginosa but an important determinant of pyocyanin production, fairly high concentrations being required for this to be maximal. We claim to have shown here that increasing the magnesium content of the medium substantially increases the resistance of this organism to gentamicin and to a lesser extent its resistance to other aminoglycosides and to polymyxin. We are unable to explain this effect, or to relate it to such other observations on the action of $\mathbf{M g}$ on Ps. aeruginosa as those of Brown and Melling (1968), but we wish to point out some of its practical implications.

One of these concerns the determination of sensitivity to gentamicin as a guide to treatment. This is an antibiotic the dose of which has to be severely limited because of the risk of toxic effects, and it is considered inadvisable that the blood concentration should be allowed to exceed $10 \mu \mathrm{g} / \mathrm{ml}$. Hence treatment is only advisable if the in vitro MIC for the causative organism is low, or a disc test suggests this. But if the MIC can vary as much as 32-fold with the composition of the medium, what reliance can be placed on a test done on one of unknown composition, or, as we should prefer to express it, of unknown $\mathrm{Mg}$ content? We have already given a reason for concluding that a medium with an adequate $\mathrm{Mg}$ content gives the more significant result.

Some difficulties in antibiotic sensitivity testing can be overcome by comparison with a standard organism. That usually employed for enterobacteria is Esch. coli, but since this and Ps. aeruginosa are differently affected in sensitivity to gentamicin by medium composition, it will not serve, as can readily be appreciated from Figure 1. The only standard organism which will serve is another strain of $P s$. aeruginosa, possessing a normal degree of sensitivity. A suitable strain might with advantage be chosen and made available for this purpose (see addendum).
These observations also have a bearing on proposals for establishing an international standard method for performing sensitivity tests. If a disc method is to be used, and measured zone diameters are to be translated into MIC and thence into agreed categories of sensitivity or resistance, it will clearly be necessary in any test of gentamicin v. Ps. aeruginosa to define medium composition with great exactitude, even perhaps to the point of prescribing limits for its magnesium content. The medium adopted in the present International Collaborative Study sponsored by WHO is Mueller-Hinton, and we have shown here that the MIC of gentamicin for Ps. aeruginosa in the liquid form of this medium is low. If this medium is to be officially adopted, it $c r$ will be necessary to ensure that agar used for $\mathcal{E}$ solidifying it has an adequate $\mathrm{Mg}$ content. This may present difficulties, since agar is a very variable product, and it can only be standardized by purification, which involves extraction of most of its mineral content.

\section{ADDENDUM}

Since this paper was written we have deposited the strain principally used in this study, which has a normal sensitivity to gentamicin and to carbenicillin, in the National Collection of Type Cultures. Its number is NCTC 10662.

\section{REFERENCES}

Barber, M., and Waterworth, P. M. (1966). Brit. med. J., 1, 203. Bechtle, R. M., and Scherr, G. H. (1958). Antibiot. \& Chemother., $8,599$.

Brown, M. R. W., and Melling, J. (1968). J. gen. Microbiol., 54, 439. Burton, M. O., Campbell, J. J. R., and Eagles, B. A. (1948). Canad. J. Res., C., 26, 15 .

Darrell, J. H., and Waterworth, P. M. (1967). Brit. med. J., 2, 535 Hanus, F. J., Sands, J. G., and Bennett, E. O. (1967). Appl. Microbiol., $15,31$.

Kunin, C. M., and Edmondson, W. P. (1968). Proc. Soc. exp. Biol (N.Y.), 129, 118.

Robinson, G. L. (1932). Brit. J. exp. Path., 13, 310.

Weinstein, M. J., Luedemann, G. M., Oden, E. M., and Wagman, G. H. (1963). Antimicrob. Agents Chemother., 1963, p. 1. 